14

\title{
Незаполненные электронные состояния ультратонких пленок тиофен-фенилен со-олигомеров на поверхности поликристаллического золота
}

\author{
(C) А.С. Комолов ${ }^{1}$, Э.Ф. Лазнева ${ }^{1}$, Н.Б. Герасимова ${ }^{1}$, В.С. Соболев ${ }^{1}$, С.А. Пшеничнюк ${ }^{2}$, \\ O.B. Борщев ${ }^{3}$, C.A. Пономаренко ${ }^{3}$, B. Handke ${ }^{4}$ \\ ${ }^{1}$ Санкт-Петербургский государственный университет, \\ Санкт-Петербург, Россия \\ ${ }^{2}$ Институт физзики молекул и кристаллов, Уфимский научный центр, РАН, \\ Уфра, Россия \\ ${ }^{3}$ Институт синтетических полимерных материалов им. Н.С. Ениколопова РАН, \\ Москва, Россия \\ ${ }^{4}$ AGH University of Science and Technology, Faculty of Material Science and Ceramics, \\ Al. Mickiewicza 30, 30-059 Kraków, Poland \\ E-mail: a.komolov@spbu.ru
}

Поступила в Редакцию 22 апреля 2020 г.

В окончательной редакции 22 апреля 2020 г.

Принята к публикации 30 апреля 2020 г.

\begin{abstract}
Приведены результаты исследования незаполненных электронных состояний в энергетическом диапазоне от 5 до $20 \mathrm{eV}$ выше уровня Ферми ультратонких пленок диметил-замещенных тиофен-фенилен со-олигомеров $\mathrm{CH}_{3}$-фенилен-тиофен-тиофен-фенилен- $\mathrm{CH}_{3}\left(\mathrm{CH}_{3}-\mathrm{PTT}-\mathrm{CH}_{3}\right)$ на два вида поверхности поликристаллического золота: ex situ Au слоя, термически осажденного в отдельной камере, и на поверхности in situ Аu, приготовленной внутри аналитической камеры. Исследования структуры пленок проводили методом дифракции рентгеновских лучей ( $X$-ray diffraction, $\mathrm{XRD})$. Обсуждается формирование суперпозиции аморфной фазы и кристаллической с периодом $3.8 \mathrm{~nm}$. Исследования энергетического расположения максимумов незаполненных электронных состояний и характера формирования пограничного потенциального барьера проводили методом спектроскопии полного тока (СПТ). Структура максимумов ТССПТ пленки $\mathrm{CH}_{3}-\mathrm{PTTP}-\mathrm{CH}_{3}$ толщиной 5-7 nm не отличалась при использовании разных видов Аu подложек и поверхности полупроводника $\mathrm{ZnO}$, приготовленной методом молекулярного наслаивания (atomic layer deposition, ALD). При осаждении слоя $\mathrm{CH}_{3}-\mathrm{PTTP}-\mathrm{CH}_{3}$ как на поверхность ex situ $\mathrm{Au}$, так и на поверхность in situ Аu наблюдалось незначительное, около $0.1 \mathrm{eV}$, повышение электронной работы выхода с увеличением толщины покрытия до 5-7 nm. При таких толщинах пленок $\mathrm{CH}_{3}-\mathrm{PTTP}_{-} \mathrm{CH}_{3}$ значения электронной работы выхода составили $4.7 \pm 0.1 \mathrm{eV}$ в случае подложки ex situ $\mathrm{Au}$ и $4.9 \pm 0.1 \mathrm{eV}$ в случае подложки in situ Au. Обсуждается возможное влияние процессов физико-химического взаимодействия на границе пленки и подложки на формирование пограничного потенциального барьера в исследованных структурах.
\end{abstract}

Ключевые слова: тиофен-фенилен со-олигомеры, ультратонкие пленки, поверхность поликристаллического $\mathrm{Au}, \mathrm{ZnO}$, электронные свойства, низкоэнергетическая электронная спектроскопия, метод молекулярного наслаивания (atomic layer deposition), метод дифракции рентгеновских лучей ( $X$-ray difraction).

DOI: 10.21883/FTT.2020.10.49931.097

\section{1. Введение}

Изучение электронных характеристик поверхностных структур на основе малых сопряженных органических молекул предоставляет значительный интерес ввиду возможного применения таких структур в разработке транзисторных, светоизлучающих устройств органической электроники [1-5]. Физико-химическое взаимодействие на границе органического материала и твердотельной поверхности сопровождается изменением электронной работы выхода поверхности, а также изменением структуры максимумов плотности электронных состояний валентной зоны и зоны проводимости $[4,6]$. Термически осажденные сверхтонкие пленки $[7,8]$ и монокристаллы тиофен-фенилен со-олигомеров (ТФСО) [9,10] продемонстрировали электронные свойства, которые могут найти применение в устройствах органической электроники. При исследованиях монокристаллических образцов ТФСО были зарегистрированы значения квантового выхода фотолюминесценции, достигающие 60\% [11-13]. В органических полевых транзисторах (OFET) на основе ТФСО значения подвижности носителей заряда достигали порядка $10^{-1} \mathrm{~cm}^{2} /(\mathrm{V} \cdot \mathrm{s})$ [12]. Увеличения подвижности носителей заряда примерно на порядок можно ожидать при использовании гибридных органических/неорганических слоев в составе OFET [14,15]. Была продемонстрирована возможность конструирования вакуумно-осажденных полупроводниковых пленок 
ТФСО $n$ - и $p$-типа проводимости $[7,8]$. При этом различия в электронных характеристиках были обусловлены использованием допантов и присоединением электроактивных функциональных групп к молекулам ТФСО. Исследования некоторых видов пленок ТФСО методом ультрафиолетовой фотоэлектронной спектроскопии (UPS) позволили установить в них структуру электронных состояний валентной энергетической зоны и зарегистрировать различия значений работы выхода исследованных пленок $n$ - и $p$-типа $[7,8,16]$.

Ранее нами были исследованы электронные состояния зоны проводимости пленок на основе бис-метил замещенных и бис-трифторометил замещенных молекул ТФСО [17,18]. В этих работах ультратонкие пленки формировали путем термического осаждения в вакууме на поверхность окисленного кремния, а измерения проводили методом спектроскопии полного тока (СПТ), которую успешно применяли для исследований и ряда других полупроводниковых органических тонкопленочных материалов $[19,20]$. СПТ результаты по установлению структуры максимумов плотности незаполненных электронных состояний плотности (DOUS) сопряженных органических материалов хорошо соответствуют результатам, полученным другими электронно-спектроскопическими методами, такими как спектроскопия электронного захвата (electron attachment spectroscopy) и спектроскопия края поглощения рентгеновских лучей (NEXAFS) [21,22]. С помощью СПТ и ряда других методик были установлены различия в характере переноса электронного заряда с поверхности кремниевой подложки в пленки ТФСО с различными замещающими функциональными группами [18,23]. При конструировании OFET устройств в качестве истокового и стокового электродов обычно используются области подложки с термически осажденным слоем золота [12]. В этой связи исследование электронных характеристик пограничной области пленок ТФСО и поверхности поликристаллического золота представляет значительный интерес. В данной статье приведены результаты исследования методом СПТ незаполненных электронных состояний зоны проводимости сверхтонких пленок бис-метил замещенных тиофен-фенилен со-олигомеров $\left(\mathrm{CH}_{3}-\mathrm{PTTP}-\mathrm{CH}_{3}\right)$ и поверхностью поликристаллического золота. Приведены результаты по исследованию формирования потенциального барьера в пограничной области органической пленки и подложки.

\section{2. Эксперимент}

В качестве подложек для нанесения органического материала использовали поверхности с термически осажденным поверх пластин ( $\mathrm{SiO} 2) n-\mathrm{Si}$ слоем $\mathrm{Au}$. Толщина слоя $\mathrm{Au}$ составляла приблизительно $50 \mathrm{~nm}$. Использовали два варианта осаждения $\mathrm{Au}$ слоя: в отдельной камере для вакуумного осаждения и последующий перенос в камеру для дальнейших исследований (ex situ)

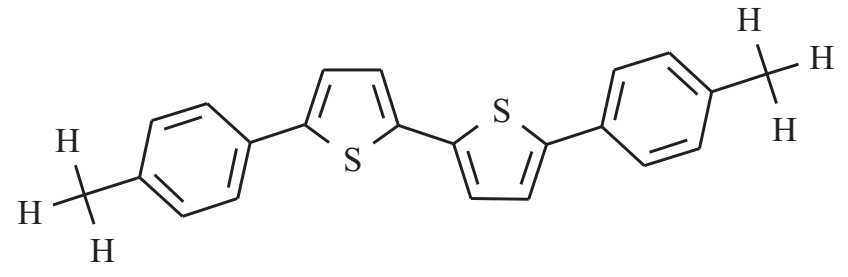

Рис. 1. Структурная формула молекул тиофен-фенилен соолигомеров с $\mathrm{CH}_{3}$ концевыми терминалами $\left(\mathrm{CH}_{3}-\mathrm{PTTP}-\mathrm{CH}_{3}\right)$.

и осаждение внутри аналитической камеры (in situ). В обоих случаях давление в процессе осаждения $\mathrm{Au}$ не повышалось более $10^{-3} \mathrm{~Pa}$. Поверхности металлов и полупроводников адсорбируют кислород- и углеродсодержащие примеси из воздуха, а также и в условиях вакуума [24-26]. Поэтому непосредственно перед нанесением органического покрытия проводили дальнейшую очистку поверхностей $\mathrm{Au}$ подложек действием фокусированного пучка Хе лампы высокого давления, которой за счет светового воздействия приводил к нагреву поверхности до $300^{\circ} \mathrm{C}$. Анализ атомного состава поверхностей $\mathrm{Au}$ подложек методом рентгеновской фотоэлектронной спектроскопии (XPS) показал приблизительно 50\% относительную концентрацию атомов $\mathrm{Au}$ на фоне примесных атомов С и О. Методом молекулярного наслаивания (atomic layer deposition, ALD) на поверхность кремниевой пластины была приготовлена подложка $\mathrm{ZnO}$. Для синтеза использовали реагенты диэтил-Zn и деионизированную воду. Температуру во время синтеза поддерживали $200-250^{\circ} \mathrm{C}$ и производили поочередное нанесение слоев атомов $\mathrm{O}$ и $\mathrm{Zn}$, как описано в работе [27]. Для осаждения органических пленок использовали покрытие $\mathrm{ZnO}$ толщиной около $100 \mathrm{~nm}$, шероховатость не превышала $5 \mathrm{~nm}$.

Для приготовления органических пленок использовали реактивы бис-метил замещенных тиофен-фенилен соолигомеров, $\mathrm{CH}_{3}$-phenylene-thiophene-thiophene-phenylene- $\mathrm{CH}_{3}\left(\mathrm{CH}_{3}-\mathrm{PTTP}-\mathrm{CH}_{3}\right)$ (рис. 1), синтезированные, как описано в работе [10]. В целях обезгаживания реактивы выдерживали в аналитической камере при базовом давлении $10^{-6} \mathrm{~Pa}$ и температуре $100^{\circ} \mathrm{C}$ в течение $2-3 \mathrm{~h}$. Осаждение покрытий $\mathrm{CH}_{3}-\mathrm{PTTP}-\mathrm{CH}_{3}$ толщиной до $10 \mathrm{~nm}$ проводили со скоростью примерно $0.1 \mathrm{~nm} / \mathrm{min}$. Во время осаждения пленок допускали повышение давления в вакуумной камере на порядок от базового давления $\left(10^{-6} \mathrm{~Pa}\right)$. Соответствие атомного состава органических покрытий химической формуле исследованных молекул было подтверждено с помощью XPS, что более подробно описано в работе [17]. Возможное структурирование пленок $\mathrm{CH}_{3}$-РТТР-CH 3 исследовали с помощью методики дифракции рентгеновких лучей ( $X$-ray diffraction, $\mathrm{XRD).} \mathrm{Пленки} \mathrm{были} \mathrm{нанесены} \mathrm{на} \mathrm{ex} \mathrm{situ} \mathrm{Au} \mathrm{подлож-}$ ку. XRD измерения проводили на дифрактометре D8 Discover (Bruker), оснащенного источником с энергией излучения $\mathrm{Cu} K_{\alpha}(0.15406 \mathrm{~nm})$. 
Измерения электронных свойств пленок $\mathrm{CH}_{3}-\mathrm{PTTP}-\mathrm{CH}_{3}$ проводили методом спектроскопии полного тока (СПТ) $[19,28]$ в процессе термического осаждения органического покрытия толщиной до $8 \mathrm{~nm}$ на поверхности подложек поликристаллического $\mathrm{Au}$. При СПТ измерениях тестирующий пучок электронов площадью поперечного сечения $0.2-0.4 \mathrm{~mm}^{2}$ направляли по нормали к исследуемой поверхности и регистрировали производную по энергии от полного тока $S(E)$, проходящего через образец в зависимости от энергии падающих электронов в диапазоне от $0 \mathrm{eV}$ до $25 \mathrm{eV}[19,28]$. СПТ предоставляет возможность определять работу выхода исследуемой поверхности относительно уровня Ферми системы, то есть величины $\left(E_{v a c}-E_{F}\right)$ с учетом калибровки инструмента [19]. Тонкая структура спектров полного тока (ТССПТ) отражает структуру расположения нижних границ особенностей DOUS в зоне проводимости $[29,30]$.

\section{3. Результаты и обсуждение}

$\mathrm{XRD}$ дифрактограмма пленок $\mathrm{CH}_{3}-\mathrm{PTTP}-\mathrm{CH}_{3}$ на $e x$ situ $\mathrm{Au}$ подложке представлена на рис. 2. Угол падения тестирующего рентгеновского пучка и угол отражения имели величину $\theta$, которую варьировали для получения дифрактограммы. В диапазоне углов $2 \theta$ от 2 до 30 градусов явно выраженных максимумов в измеренной дифрактограмме обнаружено не было (рис. 2,a). Однако после вычитания фоновой составляющей стали заметны два пика при значениях углов $2 \theta 2.3$ и 4.6 градуса (рис. $2, b)$. Такие значения углов $2 \theta$ соответствуют ре-
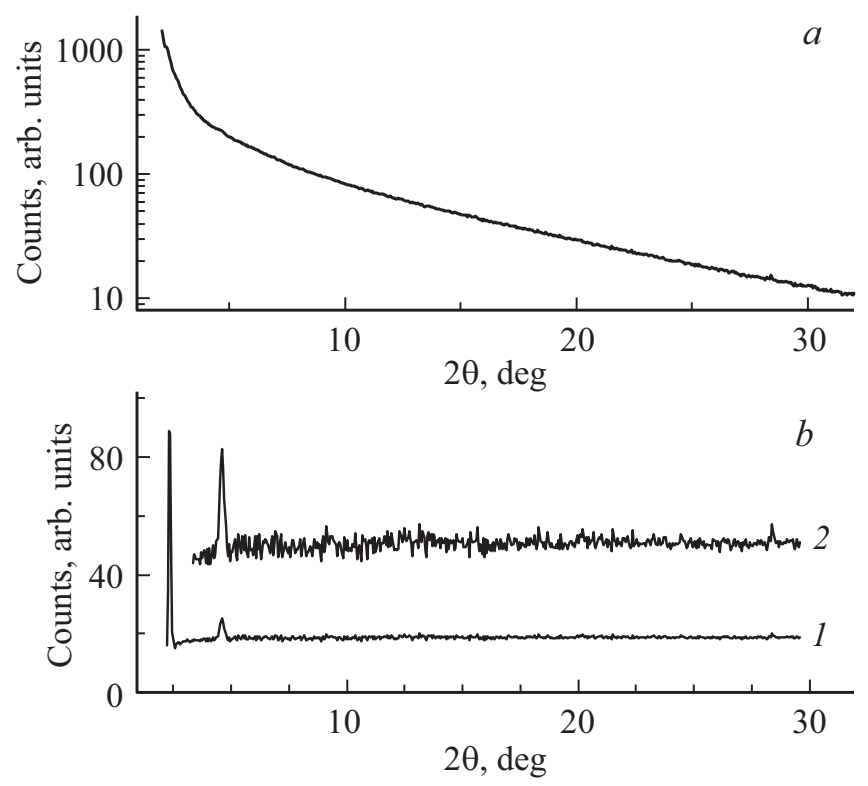

Pис. 2. XRD дифрактограмма пленок $\mathrm{CH}_{3}-\mathrm{PTTP}_{-} \mathrm{CH}_{3}$ на поверхности ex situ Au. $a-$ измеренная зависимость, $b$ - результат вычитания фоновой составляющей (кривая 1). Кривая 2 - участок кривой 1 в пятикратно увеличенном масштабе по оси Counts.

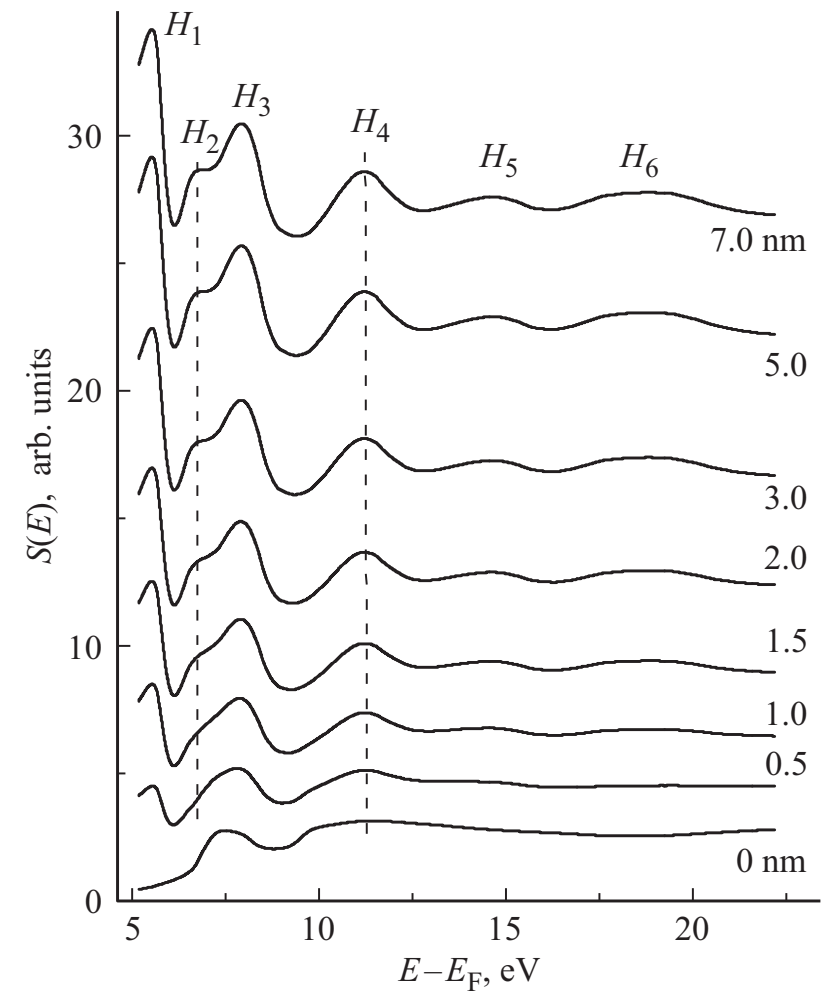

Рис. 3. ТССПТ пленок $\mathrm{CH}_{3}-\mathrm{PTTP}-\mathrm{CH}_{3}$ в процессе осаждения на поверхность ex situ Au. $H_{1}-H_{6}-$ максимумы ТССПТ, характерные для пленок $\mathrm{CH}_{3}-\mathrm{PTTP}-\mathrm{CH}_{3}$. Подписи около кривых указывают соответствующую толщину органического покрытия. Вертикальные пунктирные линии в области максимума $\mathrm{H}_{2}$ и $H_{4}$ показаны для удобства сравнения положений максимумов.

флексам от структур с периодами 3.8 и $1.9 \mathrm{~nm}$. Согласно результатам рентгеновской дифракции на монокристаллах на основе аналогичных РТTР олигомеров [10], эти значения соответствуют периоду решетки в одном из кристаллографических направлений. Ввиду малой интенсивности рефлексов и их малого количества авторы предполагают, что пленки $\mathrm{CH}_{3}-\mathrm{PTTP}_{-} \mathrm{CH}_{3}$ на ex situ $\mathrm{Au}$ подложке образованы суперпозицией кристаллической и аморфной фаз.

Серии зависимостей ТССПТ, измеренные в процессе осаждения пленок $\mathrm{CH}_{3}$-PTTP- $\mathrm{CH}_{3}$ на два вида поверхностей поликристаллического золота: поверхность ex situ $\mathrm{Au}$ и поверхность in situ $\mathrm{Au}-$ представлены на рис. 3 и $4, b$. ТССПТ, измеренные при толщине органического покрытия $0 \mathrm{~nm}$, исходят от подложек ex situ $\mathrm{Au}$ (рис. 3) и in situ Аu (рис. 4,b). ТССПТ обеих видов подложек демонстрируют по два достаточно широких максимума в области энергий 7-9eV и $10-13 \mathrm{eV}$ выше $E_{F}$. Максимумы ТССПТ в этих диапазонах энергий от поверхности термически осажденного Аи наблюдались нами и ранее [31]. Вместе с тем форма максимумов от подложки ex situ $\mathrm{Au}$ и от подложки in situ $\mathrm{Au}$ несколько отличается. Наиболее вероятно, что различия связаны со степенью очистки поверхностей. При осаждении 

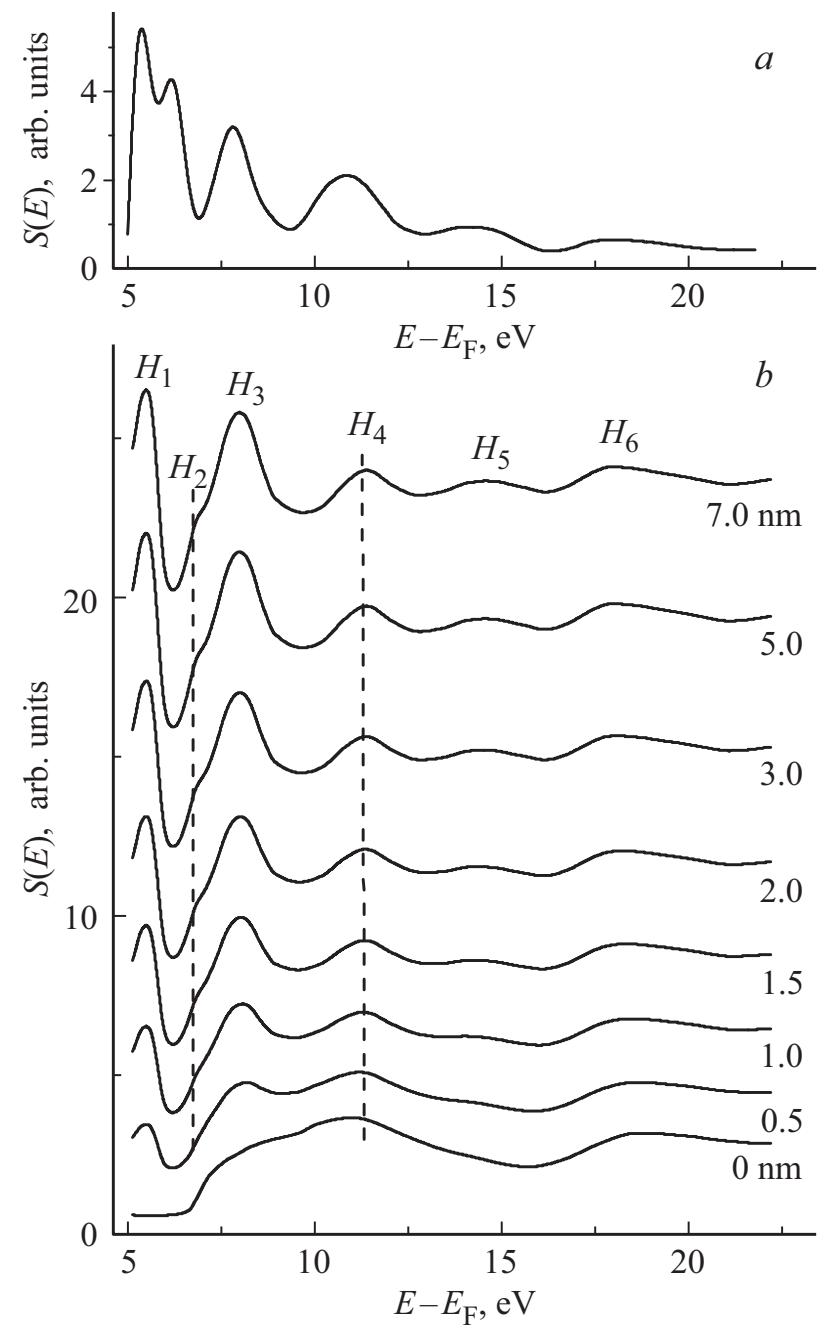

Pис. 4. $a-$ ТССПТ пленок $\mathrm{CH}_{3}-\mathrm{PTTP}-\mathrm{CH}_{3}$ на поверхности $\mathrm{ZnO}$, приготовленной методом ALD. $b-$ TCCПТ пленок $\mathrm{CH}_{3}-\mathrm{PTTP}-\mathrm{CH}_{3}$ в процессе осаждения на поверхность in situ Au. $H_{1}-H_{6}$. максимумы ТССПТ, характерные для пленок $\mathrm{CH}_{3}$-РТТР-СН ${ }_{3}$. Подписи около кривых указывают соответствующую толщину органического покрытия. Вертикальные пунктирные линии в области максимума $H_{2}$ и $H_{4}$ показаны для удобства сравнения положений максимумов.

органического покрытия ТССПТ Аu подложек затухала, и одновременно нарастала интенсивность новой ТССПТ (рис. 3 и 4,b). При толщине пленки $\mathrm{CH}_{3}-\mathrm{PTTP}-\mathrm{CH}_{3}$ 5-7 nm сформировалась стабильная ТССПТ поверхности с характерными максимумами $H_{1}-H_{6}$. Эти же максимумы ТССПТ были обнаружены нами при исследованиях пленки $\mathrm{CH}_{3}-\mathrm{PTTP}-\mathrm{CH}_{3}$ на поверхности окисленного кремния [17]. Энергетическое положение ТССПТ максимумов $H_{1}-H_{6}$ хорошо воспроизводимо и при использовании подложки $\mathrm{ZnO}$, приготовленной методом ALD (рис. 4,a). Следует отметить увеличение относительной интенсивности максимума $H_{2}$ в случае пленки $\mathrm{CH}_{3}-\mathrm{PTTP}-\mathrm{CH}_{3}$ на $\mathrm{ZnO}$ подложке, по сравнению с пленкой на подложке $\mathrm{Au}$ (рис. 4). При увеличении толщины органического покрытия до 8-10 nm ТССПТ практически не изменялась. А при дальнейшем осаждении пленки наблюдалось размытие максимумов и сдвиг их энергетического положения, вызванные зарядкой поверхности под действием падающего электронного пучка. $\pi^{*}$ или $\sigma^{*}$ характер наблюдаемых ТССПТ максимумов был установлен в работах $[17,18]$ с помощью теоретических расчетов методом теории функционала плотности для пленок $\mathrm{CH}_{3}-\mathrm{PTTP}-\mathrm{CH}_{3}$ [18] и с учетом результатов теоретических расчетов и NEXAFS исследований для пленок на основе других сопряженных органических молекул [19,32]. Таким образом, максимумы $H_{1}-H_{3}$ ТССПТ (рис. 3 и $4, b$ ) можно связать с границами $\pi^{*}$-состояний DOUS в пленках $\mathrm{CH}_{3}-\mathrm{PTTP}-\mathrm{CH}_{3}$, а максимумы $H_{4}-H_{6}$ (рис. 3 и 4,b) находятся в диапазоне, характерном для $\sigma^{*}(\mathrm{C}-\mathrm{C})$ и $\sigma^{*}(\mathrm{C}=\mathrm{C})$ максимумов DOUS.

Формирование сплошного органического покрытия $\mathrm{CH}_{3}$-PTTP-CH 3 на рассматриваемых поверхностях ех situ Au и in situ Au было показано в результате анализа интенсивностей основных максимумов подложки и пленки в ходе осаждения органического покрытия (рис. 3 и $4, b)$. Оценку интенсивностей максимумов ТССПТ проводили аналогично методу, рассмотренному в работах $[17,18]$. Так, для анализа увеличения интенсивности ТССПТ пленки $\mathrm{CH}_{3}$-РТТР-CH $H_{4}$. Для анализа затухания особенностей подложки $е x$ situ Au удобно выбрать разницу интенсивностей ТССПТ максимума при $10 \mathrm{eV}$ и минимума при $8 \mathrm{eV}$, а для анализа затухания особенностей подложки in situ $\mathrm{Au}$ удобно рассматривать разницу интенсивностей при 11 и $16 \mathrm{eV}$. Как подробно обсуждалось в работе [19], следует ожидать экспоненциального роста интенсивностей ТССПТ осаждаемого покрытия и затухания особенностей ТССПТ подложки с изменением толщины покрытия $(d)$ в случае формирования сплошного органического покрытия. Показатель этой экспоненциальной зависимости дается выражением $-2 d / \lambda[19]$, где $\lambda$ - длина свободного пробега электронов при данной энергии падающего электрона. При энергии электрона $11-12 \mathrm{eV}$ выше уровня $E_{F}$ величина $\lambda$ составляет приблизительно $3 \mathrm{~nm}$ [19,33]. На фоне экспоненциального характера нарастания интенсивностей максимумов $H_{1}-H_{6}$ (рис. 3 и $\left.4, b\right)$ их появление было обнаружено на ранней стадии осаждения, когда толщина осажденного слоя еще не достигла $0.5 \mathrm{~nm}$. Следует предположить, что поверхность Аu подложек не повлияла на структуру максимумов ТССПТ от слоя молекул, находящихся в непосредственном контакте с поверхностью подложки. Действительно, одним из механизмов формирования пограничного слоя принято считать перенос целого электронного заряда (integer charge transfer) $[4,34,35]$. Это соответствует формированию слоя молекулярных ионов на поверхности подложки, что в случае СПТ эксперимента привело бы к формированию промежуточной структуры ТССПТ, отличной от наблюдаемых максимумов $H_{1}-H_{6}$ (рис. 3 и 4,b), при толщине органического слоя до $1-1.5 \mathrm{~nm}[19,36]$. 

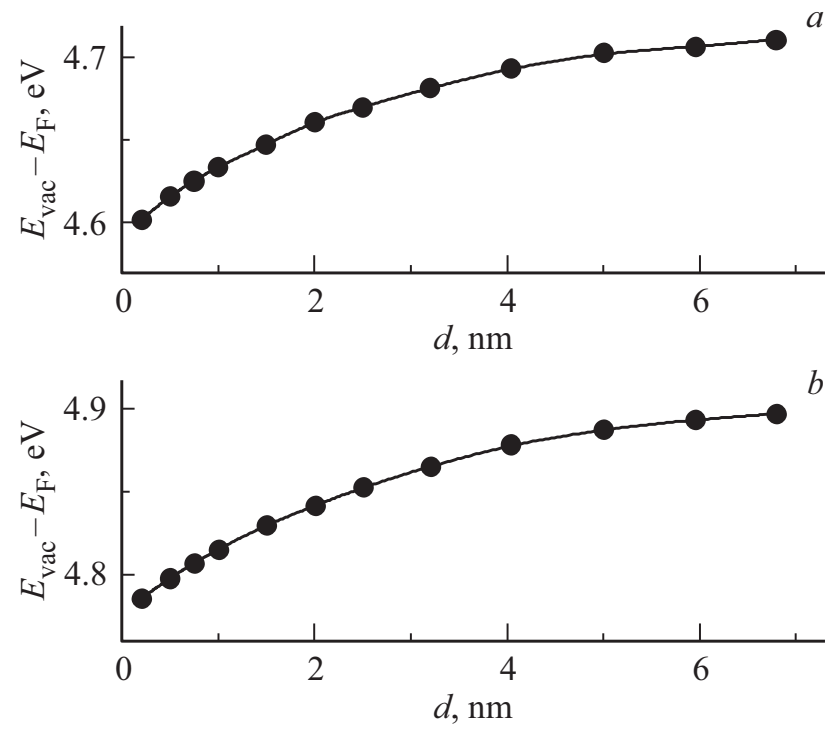

Рис. 5. Изменение положения уровня вакуума $E_{v a c}$ относительно $E_{F}$ в зависимости от толщины покрытия пленкой соолигомеров $\mathrm{CH}_{3}-\mathrm{PTTP}-\mathrm{CH}_{3}$. поверхности ex situ $\mathrm{Au}(a)$ и in situ $\mathrm{Au}(b)$.

При использовании СПТ методики значение электронной работы выхода поверхности, то есть значение $E_{v a c}$ поверхности относительно $E_{F}$ регистрируется как энергетическое положение первичного СПТ максимума. Энергия обнаружения первичного максимума отражает пороговое значение энергии электронов в падающем пучке достаточное для того, чтобы электроны стали достигать исследуемую поверхность. При увеличении напряжения смещения катода, то есть при повышении энергии электронов в пучке выше $E_{v a c}$ поверхности эксперимент дает возможность зарегистрировать ТССПТ - максимумы, отражающие незаполненные электронные состояния исследуемой поверхности. Численные значения работы выхода можно определить в результате калибровки инструмента на известных поверхностях: поверхность атомно-чистого Аu при давлении не выше $10^{-6} \mathrm{~Pa}[19,26]$, поверхность высокоупорядоченного пиролитического графита (HOPG) [1]. Изменение значения $E_{v a c}-E_{F}$ в процессе осаждения пленки $\mathrm{CH}_{3}-\mathrm{PTTP}-\mathrm{CH}_{3}$ на поверхности ex situ $\mathrm{Au}$ и in situ $\mathrm{Au}$ показано на рис. 5. Значение $E_{v a c}-E_{F}$ исходной поверхности ex situ Au составило приблизительно $4.6 \mathrm{eV}$, а исходной поверхности in situ $\mathrm{Au}$ - приблизительно $4.8 \mathrm{eV}$. C учетом размытия энергий электронов в тестирующем пучке и конечной ширины первичного СПТ максимума погрешность определения значений $E_{v a c}-E_{F}$ составляет $0.1 \mathrm{eV}$. Установленные значения работы выхода исследованных поверхностей $\mathrm{Au}$ ниже значений работы выхода, характерных для атомно-чистого $\mathrm{Au} \mathrm{и}$ лежащих в пределах 4.9-5.2 eV [1,26,31]. Это различие обусловлено наличием примесей атмосферных газов на поверхностях ех situ $\mathrm{Au}$ и in situ $\mathrm{Au}$, как обсуждалось в разделе 2, несмотря на проведенную предварительную фотоочистку и термическую очистку. Достижение полной атомной чистоты исследованных поверхностей $\mathrm{Au}$ подложек не стояло среди задач данной работы, так как, с точки зрения дизайна устройств органической электроники, интерес представляет функционирование этих устройств в условиях атмосферы, либо инертных газов, либо низкого вакуума.

При осаждении органического покрытия $\mathrm{CH}_{3}-\mathrm{PTTP}-\mathrm{CH}_{3}$ на поверхности ex situ $\mathrm{Au}$ и in situ $\mathrm{Au}$ в обоих случаях наблюдалось незначительное, около $0.1 \mathrm{eV}$, повышение работы выхода с увеличением толщины покрытия до 5-7 nm (рис. 5). Таким образом, экспериментально установленные значения работы выхода пленок $\mathrm{CH}_{3}-\mathrm{PTTP}-\mathrm{CH}_{3}$ различаются при использовании $\mathrm{Au}$ подложек разного вида и составляют $4.7 \pm 0.1 \mathrm{eV}$ в случае подложки ex situ $\mathrm{Au}$ и $4.9 \pm 0.1 \mathrm{eV}$ в случае подложки и in situ Au. При исследованиях пленок $\mathrm{CH}_{3}$-PTTР-CH 3 на поверхности $\left(\mathrm{SiO}_{2}\right) n$ - $\mathrm{Si}$ подложки нами ранее было установлено значение работы выхода этих пленок $4.0 \pm 0.1 \mathrm{eV}$ [17]. При исследованиях с помощью методики ультрафиолетовой фотоэлектронной спектроскопии пленок ТФСО, достаточно близких по структуре к исследованным в данной работе пленкам, было обнаружено, что значения электронной работы выхода лежат в пределах от 4.0 до $4.3 \mathrm{eV}[8,16]$. Из литературных данных известно, что при отсутствии взаимодействия на границе подложка/органическая пленка значение работы выхода органической пленки при толщине покрытия более $5 \mathrm{~nm}$ не зависит от выбора подложки, причем в большом количестве случаев формирование значения работы выхода происходит в еще более узком слое, толщиной $1-3 \mathrm{~nm}$ [6,34-36]. Авторы предполагают, что наблюдаемые достаточно высокие и различающиеся между собой значения работы выхода пленок $\mathrm{CH}_{3}-\mathrm{PTTP}-\mathrm{CH}_{3}$ на подложках ex situ $\mathrm{Au}$ и in situ $\mathrm{Au}$ являются следствием процессов физико-химического взаимодействия на границе пленки и подложек. Среди таких процессов, которые непосредственно влияют на взаимное расположение уровней $E_{v a c}$ и $E_{F}$, часто выделяют пиннинг (pinning) $E_{F}$ [4,35], диффузию молекул из газовой фазы и диффузию атомов металлов в органическую пленку $[26,37,38]$.

\section{4. Заключение}

Установлены закономерности формирования незаполненных электронных состояний пленок диметил замещенных тиофен-фенилен со-олигомеров $\left(\mathrm{CH}_{3}-\mathrm{PTTP}-\mathrm{CH}_{3}\right)$ на поверхности поликристаллического $\mathrm{Au}$ при использовании методики СПТ в энергетическом диапазоне от 5 до $20 \mathrm{eV}$ выше $E_{F}$. Обнаружено, что закономерности формирования пленки $\mathrm{CH}_{3}-\mathrm{PTTP}-\mathrm{CH}_{3}$ на поверхности ex situ Au слоя, термически осажденного в отдельной камере, и на поверхности $\mathrm{Au}$, приготовленной внутри аналитической камеры (in situ), имеют сходный характер. Энергетическое положение максимумов ТССПТ пленки $\mathrm{CH}_{3}-\mathrm{PTTP}-\mathrm{CH}_{3}$ толщиной 5-7 nm не изменилась при использовании разных видов 
$\mathrm{Au}$ подложек и подложки послойно осажденного $\mathrm{ZnO}$. Экспериментально установленные значения энергии $E_{v a c}$ относительно $E_{F}$, то есть электронной работы выхода пленок $\mathrm{CH}_{3}-\mathrm{PTTP}-\mathrm{CH}_{3}$ при толщине пленки 5-7 nm составляют $4.7 \pm 0.1 \mathrm{eV}$ в случае подложки $е x$ situ $\mathrm{Au}$ и $4.9 \pm 0.1 \mathrm{eV}$ в случае подложки in situ Au.

\section{Финансирование работы}

Работа выполнена при поддержке грантов РФФИ (18-03-00020, 18-03-00179). Синтез $\mathrm{CH}_{3}-\mathrm{PTTP}_{-} \mathrm{CH}_{3}$ выполнен в рамках Госзадания ИСПМ РАН при поддержке Министерства науки и высшего образования. Исследования слоев $\mathrm{ZnO}$ выполнены при поддержке гранта РФФИ (20-03-00026). В работе использовали оборудование Научного парка СПбГУ „Физические методы исследования поверхности“, „Инновационные технологии композитных наноматериалов“, „Рентгенодифракционные методы исследования“".

\section{Конфликт интересов}

Авторы заявляют, что у них нет конфликта интересов.

\section{Список литературы}

[1] Y. Zhou, C. Fuentes-Hernandez, J. Shim, J. Meyer, A.J. Giordano, H. Li, P. Winget, T. Papadopoulos, H. Cheun, J. Kim, M. Fenoll, A. Dindar, W. Haske, E. Najafabadi, T.M. Khan, H. Sojoudi, S. Barlow, S. Graham, J.L. Brédas, S.R. Marder, A. Kahn, B. Kippelen. Science 336, 327 (2012).

[2] А.С. Сизов, Е.В. Агина, С.А. Пономаренко. Успехи химии 87, 1226 (2018).

[3] L. Grzadziel, M. Krzywiecki, G. Genchev, A. Erbe. Synth. Met. 223, 199 (2017).

[4] M. Gruenewald, L.K. Schirra, P. Winget, M. Kozlik, P.F. Ndione, A.K. Sigdel, J.J. Berry, R. Forker, J.-L. Brédas, T. Fritz, O.L.A. Monti. J. Phys. Chem. C 119, 4865 (2015).

[5] B. Handke, L. Klita, W. Niemiec. Surf. Sci. 666, 70 (2017).

[6] I.G. Hill, J. Schwartz, A. Kahn. Organic Electr. 1, 5 (2000).

[7] T. Sengoku, T. Yamao, S. Hotta, J. Non-Cryst. Solids 358, 2525 (2012).

[8] F. Sasaki, Y. Kawaguchi, H. Mochizuki, S. Haraichi, T. Ishitsuka, T. Ootsuka, T. Tomie, S. Watanabe, Y. Shimoi, T. Yamao, S. Hotta. Mol. Cryst. Liq. Cryst. 620, 153 (2015).

[9] M.S. Kazantsev, V.G. Konstantinov, D.I. Dominskiy, V.V. Bruevich, V.A. Postnikov, Y.N. Luponosov, V.A. Tafeenko, N.M. Surin, S.A. Ponomarenko, D.Y. Paraschuk. Synt. Met. 232, 60 (2017).

[10] V.A. Postnikov, Y.I. Odarchenko, A.V. Iovlev, V.V. Bruevich, A.Y. Pereverzev, L.G. Kudryashova, V.V. Sobornov, L. Vidal, D. Chernyshov, Y.N. Luponosov, O.V. Borshchev, N.M. Surin, S.A. Ponomarenko, D.A. Ivanov, D.Y. Paraschuk. Cryst. Growth Des. 14, 1726 (2014).

[11] А.С. Сизов, Е.В. Агина, С.А. Пономаренко. Успехи химии 88, 1220 (2019).

[12] L.G. Kudryashova, M.S. Kazantsev, V.A. Postnikov, V.V. Bruevich, Y.N. Luponosov, N.M. Surin, O.V. Borshchev, S.A. Ponomarenko, M.S. Pshenichnikov, D.Y. Paraschuk. ACS Appl. Mater. Interfaces 8, 10088 (2016).
[13] Y. Yomogida, T. Takenobu, H. Shimotani, K. Sawabe, S.Z. Bisri, T. Yamao, S. Hotta, Y. Iwasa. Appl. Phys. Lett. 97, 173301 (2010).

[14] А.Н. Алешин, И.П. Щербаков, Д.А. Кириленко, Л.Б. Матюшкин, В.А. Мошников. ФТТ 61, 388 (2019).

[15] П.С. Крылов, А.С. Берестенников, С.А. Фефелов, А.С. Комолов, А.Н. Алешин. ФТТ 58, 2476 (2016).

[16] Y. Kawaguchi, F. Sasaki, H. Mochizuki, T. Ishitsuka, T. Tomie, T. Ootsuka, S. Watanabe, Y. Shimoi, T. Yamao, S. Hotta. J. Appl. Phys. 113, 083710 (2013).

[17] А.С. Комолов, Э.Ф. Лазнева, Н.Б. Герасимова, Ю.А. Панина, Г.Д. Зашихин, С.А. Пшеничнюк, О.В. Борщев, С.А. Пономаренко, В. Handke. ФТТ 60, 1012 (2018).

[18] A.S. Komolov, E.F. Lazneva, N.B. Gerasimova, Yu.A. Panina, V.S. Sobolev, A.V. Koroleva, S.A. Pshenichnyuk, N.L. Asfandiarov, A. Modelli, B. Handke, O.V. Borshchev, S.A. Ponomarenko. J. Electron Spectr. Rel. Phenom. 235, 40 (2019).

[19] A.S. Komolov, E.F. Lazneva, S.N. Akhremtchik, N.S. Chepilko, A.A. Gavrikov. J. Phys. Chem. C 117, 24, 12633 (2013).

[20] А.С. Комолов, Э.Ф. Лазнева, Н.Б. Герасимова, Ю.А. Панина, А.В. Барамыгин, Г.Д. Зашихин, С.А. Пшеничнюк. ФТТ 58, 367 (2016).

[21] S.A. Pshenichnyuk, A. Modelli, E.F. Lazneva, A.S. Komolov. J. Phys. Chem. A 120, 2667 (2016).

[22] Y. Tong, F. Nicolas, S. Kubsky, H. Oughaddou, F. Sirotti, V. Esaulov, A. Bendounan. J. Phys. Chem. C 121, 9, 5050 (2017).

[23] A.Y. Sosorev, M.K. Nuraliev, E.V. Feldman, D.R. Maslennikov, O.V. Borshchev, M.S. Skorotetcky, N.M. Surin, M.S. Kazantsev, S.A. Ponomarenko, D.Y. Paraschuk. Phys. Chem. Chem. Phys. 21, 11578 (2019).

[24] A.S. Komolov, Y.M. Zhukov, E.F. Lazneva, A.N. Aleshin, S.A. Pshenichnuk, N.B. Gerasimova, Yu.A. Panina, G.D. Zashikhin, A.V. Baramygin. Mater. Des. 113, 319 (2017).

[25] И.А. Аверин, А.А. Карманов, В.А. Мошников, И.А. Пронин, С.Е. Игошина, А.П. Сигаев, Е.И. Теруков. ФТТ 57, 2304 (2015).

[26] J. Hwang, A. Wan, A. Kahn. Mater. Sci. Eng. R 64, 1 (2009).

[27] С.А. Кукушкин, А.В. Осипов, А.И. Романычев. ФТТ 58, 1398 (2016).

[28] A.S. Komolov, E.F. Lazneva, S.N. Akhremtchik. App. Surf. Sci. 256, 2419 (2010).

[29] I. Bartos. Progr. Surf. Sci. 59, 197 (1998).

[30] A.S. Komolov, P.J. Møller, Y.G. Aliaev, E.F. Lazneva, S.A. Akhremchik, F.S. Kamounah, J. Mortenson, K. Schaumburg. J. Molec. Struct. 744/747, 145 (2005).

[31] A.S. Komolov, P.J. Moeller. Appl. Surf. Sci. 244, 573 (2005).

[32] Y. Stöhr Y. NEXAFS Spectroscopy. Springer, Berlin (2003).

[33] T. Graber, F. Forster, A. Schoell, F. Reinert. Surf. Sci. 605, 878 (2011).

[34] A.L. Shu, W.E. McClain, J. Schwartz, A. Kahn. Organic Electron. 15, 2360 (2014).

[35] S. Braun, W. Salaneck, M. Fahlman. Adv. Mater. 21, 1450 (2009).

[36] A.S. Komolov, P.J. Moeller. Synth. Met. 138, 119 (2003).

[37] A.S. Komolov, S.N. Akhremtchik, E.F. Lazneva. Spectrochim. Acta A 798, 708 (2011).

[38] M. Krzywiecki, L. Grzadziel, P. Powroznik, M. Kwoka, J. Rechmann, A. Erbe. Phys. Chem. Chem. Phys. 20, 16092 (2018).

Редактор К.В.Емцев 